\title{
Therapy with Lapatinib: Current Status in Women with Advanced Breast Cancer
}

\author{
Michael Untch ${ }^{\mathrm{a}} \quad$ Christian Jackisch ${ }^{\mathrm{b}}$ \\ a Interdisziplinäres Brustzentrum, Helios-Klinikum Berlin-Buch, Akademisches Lehrkrankenhaus der Charité - Universitätsmedizin Berlin, \\ ${ }^{b}$ Klinik für Gynäkologie und Geburtshilfe \& Brustzentrum, Klinikum Offenbach GmbH, Germany
}

\section{Key Words}

Breast cancer · HER-1/HER-2 overexpression ·

Trastuzumab resistance Tyrosine kinase inhibitor . Lapatinib

\section{Summary}

HER-2 overexpression occurs in $20-30 \%$ of women with breast cancer and is associated with poor prognosis and reduced overall survival. The small molecule lapatinib is an orally administered dual receptor tyrosine kinase inhibitor of HER-1 and HER-2. Preclinical in vitro and in vivo models as well as early clinical trials provided evidence that lapatinib is active against breast cancer. Women with advanced or metastatic HER-2-positive breast cancer have limited therapeutic options once their disease has progressed on trastuzumab and standard initial chemotherapy regimens. There has been a clear need for alternative treatments in this advanced setting. In a recently published phase III trial, lapatinib combined with capecitabine has demonstrated superior efficacy over capecitabine alone in this group of patients, with a median time to tumor progression of 8.4 months in the combination therapy group versus 4.4 months in the monotherapy arm. This improvement was achieved without an increase in serious toxic effects or symptomatic cardiac events.

\section{Introduction}

Breast cancer is frequently associated with overexpression or mutation of the epidermal growth factor receptor (EGFR) tyrosine kinases, which is associated with aggressive disease bi-

\author{
Schlüsselwörter \\ Mammakarzinom · HER-1/HER-2-Überexpression · \\ Trastuzumab-Resistenz · Tyrosinkinase-Inhibitor . \\ Lapatinib
}

\section{Zusammenfassung}

Bei $20-30 \%$ der Patientinnen mit Mammakarzinom findet sich eine Überexpression von HER-1- und HER-2-Rezeptoren, was mit einer schlechten Prognose und reduziertem Gesamtüberleben assoziiert ist. Das kleine Molekül ("small molecule») Lapatinib hemmt, oral verabreicht, die Tyrosinkinase-Komponenten von HER-1 und HER-2. Präklinische In-vitro- und In-vivo-Untersuchungen sowie frühe klinische Studien zeigten, dass Lapatinib eine antitumorale Aktivität bei Brustkrebs entfaltet. Für Patientinnen mit fortgeschrittenem oder metastasiertem HER-2positivem Mammakarzinom, die unter Therapie mit Trastuzumab und anderen First-line-Standardschemata ein Rezidiv erlitten, waren die Behandlungsoptionen bisher limitiert, so dass für dieses Kollektiv dringend alternative Therapien benötigt wurden. In einer kürzlich publizierten Phase-III-Studie erwies sich Lapatinib in Kombination mit Capecitabin der Capecitabin-Monotherapie mit einer medianen Zeit bis zur Tumorprogression von 8,4 Monaten versus 4,4 Monaten als deutlich überlegen. Dieser Therapieeffekt konnte ohne Häufung schwerwiegender Nebenwirkungen oder symptomatischer kardialer Ereignisse erzielt werden.

ology, leading to poor clinical outcome, including short survival time and short time to relapse [1-3].

The EGFR family of receptors consists of the four closely related members EGFR/ErbB1, HER-2/ErbB2, HER-3/ErbB3, and HER-4/ErbB4. All receptors have an extracellular do-

\begin{tabular}{|c|c|}
\hline KARGER & (C) 2007 S. Karger GmbH, Freiburg \\
\hline $\begin{array}{l}\text { Fax +49 } 7614520714 \\
\text { E-mail Information@Karger.de } \\
\text { www.karger.com }\end{array}$ & $\begin{array}{l}\text { Accessible online at: } \\
\text { www.karger.com/brc }\end{array}$ \\
\hline
\end{tabular}

Prof. Dr. med. Michael Untch

Interdisziplinäres Brustzentrum, Helios Klinikum Berlin-Buch

Akademisches Lehrkrankenhaus der Charité

Wiltbergstraße 50,13125 Berlin, Germany

Tel. +49 30 9401-2275, Fax -4326

E-mail muntch@berlin.helios-kliniken.de 
main responsible for ligand binding, a helical transmembrane segment, and an intracellular protein tyrosine kinase (TK) domain. Ligand binding to these receptors induces either receptor homodimerization or heterodimerization, resulting in receptor autophosphorylation, which activates various downstream signalling pathways that regulate cell proliferation, growth, differentiation, and survival.

EGFR overexpression occurs in about $27-30 \%$ of breast tumors, and HER-2 is overexpressed in an estimated $20-25 \%$ of the breast cancers [4]. Therefore, EGFR and HER-2 have emerged as attractive and logical targets for the design of anticancer therapeutics such as monoclonal antibodies that inhibit the receptor (e.g. trastuzumab, Herceptin ${ }^{\circledR}$, Roche Pharma AG, Grenzach-Wyhlen, Germany) and agents that inhibit receptor TKs (e.g. gefitinib, Iressa ${ }^{\circledR}$, Novartis Pharma AG, Nürnberg, Germany; erlotinib, Tarceva ${ }^{\circledR}$, Roche Pharma AG).

\section{Rationale for Developing Lapatinib}

Lapatinib (Tyverb ${ }^{\circledR}$, Glaxo-SmithKline GmbH \& Co. KG, München, Germany) is a novel orally active small molecule. Due to its TK domain inhibition of both EGFR and HER-2 it is classified as a dual TK inhibitor. Lapatinib works by reversibly binding to the cytoplasmic ATP-binding site of the kinase and blocking receptor phosphorylation and activation, thereby preventing subsequent downstream signalling events $[5]$.

The ability to specifically inhibit EGFR and HER-2 is relatively unique among the small-molecule TK inhibitors and contrasts with the effects of the licensed TK inhibitors gefitinib and erlotinib which only target EGFR.

The rationale for the development of a dual EGFR/HER-2 TK inhibitor is based on several reasons. First, an inhibitor of one TK alone may not be as effective at inhibiting heterodimers containing both ErbB1 and ErbB2 [6]. Furthermore, synergistic inhibition of cancer cell growth has been demonstrated with simultaneous targeting of EGFR and HER-2, resulting in more potent inhibition in cell growth compared with targeting either EGFR or HER-2 alone [7]. Third, simultaneous inhibition of EGFR and HER-2 may overcome redundancy in cell signalling pathways, a form of resistance observed in single TK inhibition in which upregulation of other members of the HER subfamily occurs [8].

\section{Preclinical Data}

Several preclinical studies using various breast cancer cell lines that overexpress either EGFR or HER-2 have shown the in vitro activity of lapatinib. For example, treatment with lapatinib over 77 days in long-term in vivo studies with human breast cancer xenografts in athymic mice resulted in a sustained and significant reduction in xenograft volume com-

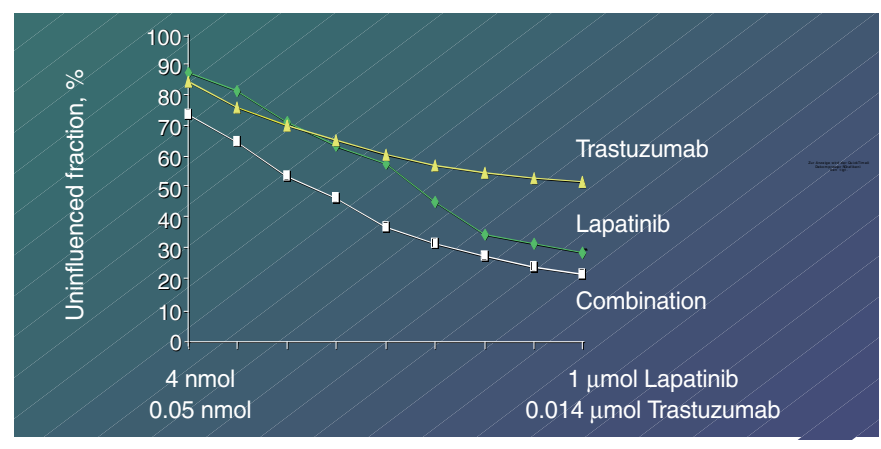

Fig. 1. Synergistic efficacy of lapatinib and trastuzumab in HER-2-overexpressing breast cancer xenografts in athymic mice [mod. from 9].

pared with untreated controls [9]. For the combination of lapatinib plus trastuzumab, synergistic drug interactions were observed in 4 different HER-2-overexpressing cell lines (fig. 1). In breast cancer cells that overexpress a truncated but activated form of HER-2 (p95erbB2), HER-2 preferentially forms heterodimers with HER-3 and is regulated by heregulin (a HER-3 ligand) and not EGF [10]. As such, the HER-2-positive cells were resistant to the monoclonal antibody trastuzumab, but sensitive to lapatinib. The dual EGFR/HER-2 TK inhibitor has also been shown to restore tamoxifen sensitivity in estrogen receptor (ER)-positive, tamoxifen-resistant breast cancer models [11]. Treatment of MCF-7(pr), T-47D, and ZR75 cells with lapatinib or tamoxifen alone caused an incomplete cell cycle arrest. Treatment with both drugs led to a more rapid and profound cell cycle arrest in all 3 lines. Finally, lapatinib increased the sensitivity of EGFR-positive primary human breast cancer cell lines to the effect of radiation [12].

\section{Clinical Phase I Trials}

These encouraging preclinical results have prompted the initiation of several phase I studies to determine the feasibility and safety as well as the efficacy of the novel, dual EGFR/HER-2 TK inhibitor in the clinical setting. Burris et al. treated 67 heavily pretreated patients with HER-1-expressing and/or HER-2-overexpressing metastatic solid tumors in 5 different dosages ranging from 500 to $1,600 \mathrm{mg}$ once daily for 20 days (EGF 10004 study) [13]. The most frequently reported drugrelated adverse events were diarrhea (42\%) and rash (31\%). No grade 4 drug-related adverse events were reported. Five grade 3 drug-related toxicities (gastrointestinal events and rash) were experienced by 4 patients. Drug-related interstitial pneumonitis or cardiac dysfunction associated with other HER-targeted therapies was not reported. Four patients with trastuzumab-resistant metastatic breast cancer had partial responses (PRs). Twenty-four patients with various other carcinomas experienced stable disease (SD), of whom 10 received lapatinib for at least 6 months. 
In addition, several phase I studies have been conducted using lapatinib in combination with conventional therapies for breast cancer. Based on the synergy between trastuzumab and taxanes, lapatinib has been combined with paclitaxel both in the three-times-weekly and weekly schedules in 56 heavily pretreated breast cancer patients (EGF 10009 study) [14]. Lapatinib $(1,500 \mathrm{mg} /$ day $)$ and paclitaxel $\left(175 \mathrm{mg} / \mathrm{m}^{2} 3\right.$ weekly or $80 \mathrm{mg} / \mathrm{m}^{2}$ weekly for 3 out of 4 weeks) were well tolerated and active.

As Storniolo et al. reported, the combination of lapatinib (1,000 mg/day) with trastuzumab (standard dose: $4 \mathrm{mg} / \mathrm{kg}$ intravenously as initial loading dose, followed by $2 \mathrm{mg} / \mathrm{kg}$ i.v. weekly) in 54 heavily pretreated trastuzumab-refractory patients with metastatic breast cancer induced a complete response (CR) or a PR in $22 \%$ of subjects and SD in $37 \%$ (EGF 10023 study) [15].

Finally, Schwartz et al. demonstrated a well-tolerated safety profile and evidence of clinical activity of combining lapatinib $1,250 \mathrm{mg} /$ day with capecitabine $2,000 \mathrm{mg} / \mathrm{m}^{2}$ [16].

\section{Clinical Phase II Studies in Advanced Breast Cancer}

Based on the good early data reported, lapatinib was examined in active phase II trials either in refractory advanced/ metastatic breast cancer or as first-line therapy. These include two randomized phase II studies that were looking at the efficacy of single-agent lapatinib in patients with refractory metastatic breast cancer. In the nonrandomized, open-label, multicenter phase II study EGF 20002, 78 patients with HER2-overexpressing metastatic breast cancer and progressive disease on prior trastuzumab-containing regimens were treated with lapatinib daily at a dose of $1,500 \mathrm{mg}$ [17]. In the preliminary analysis, the clinical benefit rate $(\mathrm{CBR}=\mathrm{CR}+\mathrm{PR}+\mathrm{SD})$ was $22 \%$.

The second phase II study EGF 20008 included more than 200 patients with either HER-2-positive (cohort A) or negative (cohort B) metastatic breast cancer who developed progressive disease following prior treatment with anthracyclines, taxanes, and capecitabine [18]. Study medication consisted of $1,500 \mathrm{mg} /$ day lapatinib. While there has been no final efficacy report from this second phase II study, an investigator-reported analysis of the first 81 patients combined from both trials reported that 19 women $(23 \%)$ were progression-free at 16 weeks and $7(8.6 \%)$ had an objective tumor response $[5,19]$. A combined biomarker analysis was also conducted for these two studies, to determine the relevant tissue and serum biomarkers that would predict the response to single-agent lapatinib $[4,19]$. Tumors were stained by immunohistochemistry (IHC) for EGFR to HER-4, insulin-like growth factor 1 receptor (IGF1R), truncated HER-2 (p95), heregulin, and pERK-1/2. The initial data showed that metastatic breast cancer patients were more likely to respond to lapatinib if their disease was ER-negative, progesterone receptor $(\mathrm{PgR})$-nega- tive, and HER-2-overexpressing. In addition, a decline in serum HER-2 extracellular domain after 4 and 8 weeks of lapatinib therapy correlated with clinical response.

Studies with lapatinib in the first-line setting showed also a promising activity. In the phase II EGF 20009 study, locally advanced or metastatic breast cancer patients with HER-2 amplification, documented by fluorescence in situ hybridization (FISH), who had not received prior trastuzumab for metastatic disease were randomized to receive lapatinib as first-line monotherapy at a dose of either $1,500 \mathrm{mg}$ qd or $500 \mathrm{mg}$ bid [20]. The interim analysis in the first 40 patients reported an objective PR of $35 \%$, with an additional $35 \%$ patients with SD at 12 weeks. These findings for overall antitumor efficacy are comparable to the reported response rates for single-agent trastuzumab as first-line treatment for HER-2-positive metastatic breast cancer [5].

\section{Clinical Phase III Study}

Based on the encouraging results of the phase I trial of lapatinib in combination with capecitabine, demonstrating a welltolerated safety profile and evidence of clinical activity [16], a phase III, randomized, open-label study comparing lapatinib in combination with capecitabine with capecitabine alone was conducted (EGF 100151 study) [21]. Given the fact that the primary endpoint was exceeded and due to the absence of safety concerns, the Independent Data Monitoring Committee recommended halting enrolement and reporting the results. 392 women with HER-2-positive, locally advanced or metastatic breast cancer (T4 primary tumor and stage IIIB or IIIC disease) that had progressed after treatment with regimens that included an anthracycline, a taxane, and trastuzumab were randomly assigned to receive either oral lapatinib $(1,250 \mathrm{mg}$ qd continuously) in combination with oral capecitabine $\left(2,000 \mathrm{mg} / \mathrm{m}^{2} /\right.$ day on days $\left.1-14 ; \mathrm{n}=160\right)$ or thirdline regimen capecitabine monotherapy $\left(2,500 \mathrm{mg} / \mathrm{m}^{2} /\right.$ day on days $1-14 ; n=161$ ) every 3 weeks. The groups were well balanced in terms of patient characteristics and disease characteristics. In both groups, more than $97 \%$ of patients had received prior therapy with anthracyclines, over $98 \%$ were also treated with taxanes, and $97 \%$ of patients had received prior trastuzumab. The primary endpoint was time to progression (TTP), secondary endpoints encompassed overall survival (OS), progression-free survival (PFS), overall response (ORR) and CBR, as well as safety. Women were assessed every 6 weeks for the first 24 weeks, then every 12 weeks while they were receiving the study treatment. Evaluation of the left ventricular ejection fraction (LVEF) by echocardiography or multiple gated acquisition scanning was performed at the time of the efficacy assessments with the use of the same technique for the duration of the study.

A total of 155 of 163 women in the combination therapy group (95\%) and 145 of 161 women in the monotherapy group 


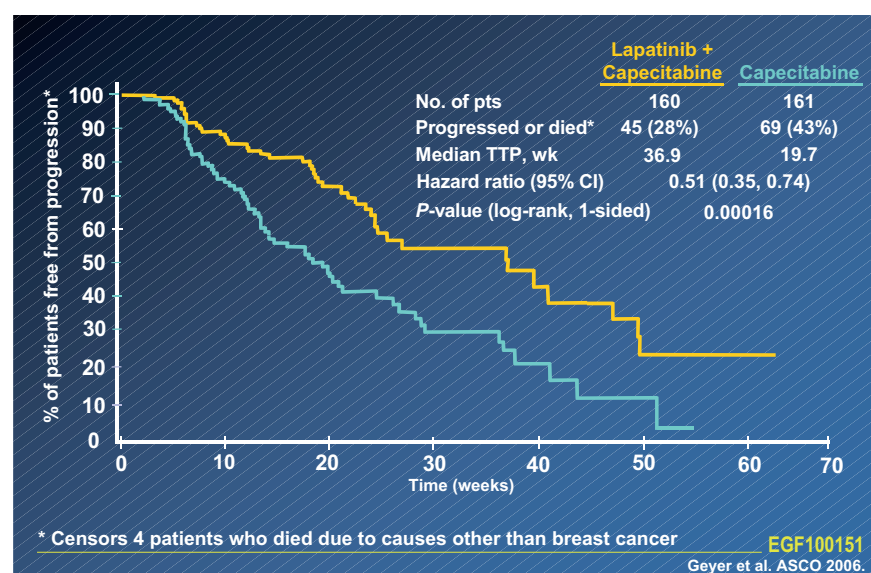

Fig. 2. Phase III EGF100151 study: time to progression (TTP; ITT population) [mod. from 21]

$(90 \%)$ received the randomly assigned treatment. The interim analysis of TTP met specified criteria for early reporting on the basis of superiority in the combination therapy group. The hazard ratio for the independently assessed TTP was 0.51 (95\% confidence interval, CI: $0.35-0.74 ; p=0.00016$ ), with 45 events in the combination group and 69 events in the monotherapy group (fig. 2). The median TTP was 8.4 months in the combination therapy group, as compared with 4.4 months under monotherapy (table 1).

The overall response rate was $22 \%$ (95\% CI: 16-29) in the combination therapy arm and $14 \%$ (95\% CI: 9-21) in the monotherapy arm $(\mathrm{p}=0.09)$ (table 1$)$. The corresponding CBRs were $27 \%$ for the combination therapy group and $18 \%$ for the monotherapy arm. Twenty nine deaths occurred in each therapy group (hazard ratio: 0.93 ; $95 \%$ CI: $0.55-1.59$; $\mathrm{p}=0.800)$ (fig. 3).

Additional analyses of trial data showed that the incidence of CNS or brain metastases was also lower in patients in the combination treatment arm. Only 4 patients receiving the combination therapy experienced CNS relapse versus 11 of those on capecitabine alone ( $\mathrm{p}=0.10$ by Fisher's exact test $)$.

As compared with capecitabine alone, lapatinib plus capecitabine was not associated with an increase in either serious toxic effects or rates of discontinuation related to adverse events $(n=22$ under combination therapy, $n=18$ in the monotherapy group). The most common adverse events included diarrhea, hand-foot syndrome, nausea, fatigue, and rash that was distinct from the hand-foot syndrome.

There were no differences in the mean LVEF values between the two groups at scheduled assessments. In the combination arm, 4 women experienced asymptomatic cardiac events that were considered to be treatment related and fully recovered, while one patient in the capecitabine monotherapy group experienced a cardiac event unrelated to treatment that remained unresolved. No symptomatic cardiac events were observed, and there were no withdrawals from treatment due to

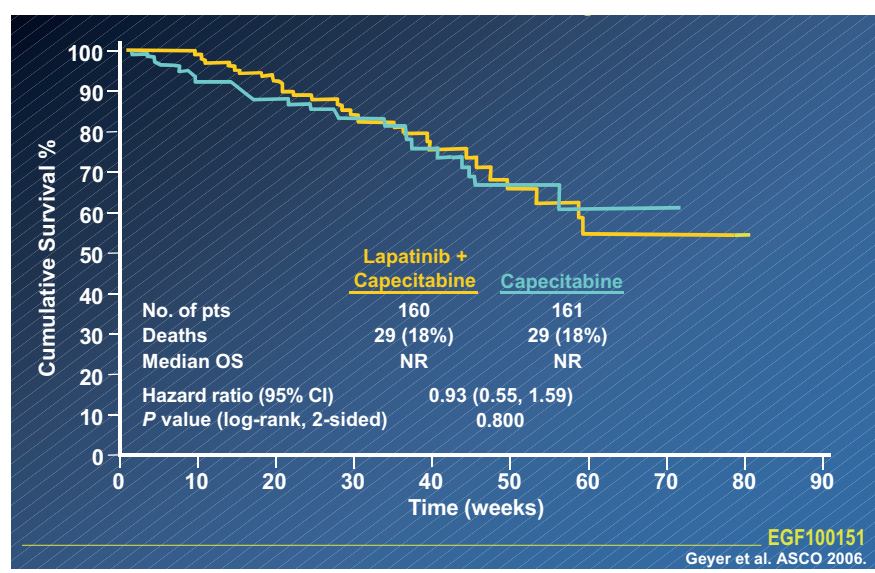

Fig. 3. Phase III EGF100151 study: overall survival (OS; ITT population) [mod. from 21].

Table 1. Phase III EGF 100151 study: efficacy endpoints in the intentionto-treat population [mod. from 21]

\begin{tabular}{lllll}
\hline & $\begin{array}{l}\mathrm{L} / \mathrm{C} \\
(\mathrm{n}=163)\end{array}$ & $\begin{array}{l}\mathrm{C} \\
(\mathrm{n}=161)\end{array}$ & HR & p value \\
\hline Median TTP, months & 8.4 & 4.4 & 0.49 & $<0.001^{\mathrm{a}}$ \\
Median PFS, months & 8.4 & 4.1 & 0.47 & $<0.001^{\mathrm{a}}$ \\
OS, \% & 22 & 14 & & \\
CR, n (\%) & $1(<1)$ & $0(0)$ & & $0.09^{\mathrm{b}}$ \\
PR, n (\%) & $35(21)$ & $23(14)$ & & \\
CBR, n (\%) & $44(27)$ & $29(18)$ & & \\
Deaths, n (\%) & $36(22)$ & $35(22)$ & & \\
\hline
\end{tabular}

TTP = Time to progression; PFS = progression-free survival; OS = overall survival; $\mathrm{CR}=$ complete response; $\mathrm{PR}=$ partial response $\mathrm{CBR}=$ clinical benefit rate; $\mathrm{L} / \mathrm{C}=$ lapatinib plus capecitabine; $\mathrm{C}=$ capecitabine alone; $\mathrm{HR}=$ hazard ratio.

${ }^{\mathrm{a} C a l c u l a t e d}$ with the log-rank test.

${ }^{\mathrm{b}}$ Calculated with Fisher's exact test.

declines in LVEF, no cases of congestive heart failure, and no decreases in the mean LVEF values in the group receiving lapatinib.

As concluded by the authors, the results of the EGF 100151 study provide support for the use of lapatinib and capecitabine in women with progression of HER-2-positive breast cancer after treatment with trastuzumab. The findings also warrant evaluation of the role of lapatinib earlier in the treatment of HER-2-positive breast cancer. This will be done in the first phase III study TEACH $\left(\right.$ Tykerb $^{\circledR}$ Evaluation After Chemotherapy) to investigate whether adjuvant treatment with lapatinib will improve disease-free survival in women with early-stage HER-2-positive breast cancer, including those with positive and negative node involvement. The trial is open for patients who received their adjuvant treatment before trastuzumab was registered and who have now the chance to 
receive an anti-HER-2 treatment. Approximately 3,000 women will be enrolled from 450 centers in more than 30 countries. Patients will be randomized to receive lapatinib $1,500 \mathrm{mg}$ or matching placebo orally administered once daily. Women will continue treatment for a maximum of 12 months or until disease recurrence, development of a second primary cancer, withdrawal from study drug due to unacceptable toxicity, or consent withdrawal. All women will be followed until death or until study closure. Disease-free survival was defined as the primary efficacy endpoint.

Based on these positive data, lapatinib has been approved on March 2007 by FDA in combination with capecitabine for the treatment of patients with advanced or metastatic breast cancer whose tumors overexpress HER-2 and who have received prior therapy including an anthracycline, a taxane and trastuzumab. Lapatinib is submitted for marketing approval in the
European Union and Switzerland for the treatment of advanced or metastatic HER-2-positive breast cancer in women who have progressed despite prior therapy, including trastuzumab. Registration dossiers have also been filed in Australia, Canada, and New Zealand.

Given the good results in the metastatic setting, lapatinib moves forward in early breast cancer trials: ALTTO study Adjuvant Lapatinib and/or Trastuzumab Treatment Optimization; Neo-ALLTO study - Adjuvant Lapatinib and/or Trastuzumab Treatment Organization Study: a randomized, multicenter, open-label phase III study of neoadjuvant lapatinib, trastuzumab, and their combination plus paclitaxel; Geparquinto study - lapatinib into current neoadjuvant chemotherapy regimes for primary breast cancer with HER-2/neu overexpression compared to trastuzumab.

\section{References}

$\checkmark 1$ Yarden Y: Biology of HER2 and its importance in breast cancer. Oncology 2001;61(suppl 2):1-13.

2 Stern DF: Tyrosine kinase signalling in breast cancer: ErbB family receptor tyrosine kinases. Breast Cancer Res 2000;2:176-183.

3 Nahta R, Hortobágyi GN, Esteva FJ: Growth factor receptors in breast cancer: potential for therapeutic intervention. Oncologist 2003;8:5-17.

4 Moy B, Goss P: Lapatinib: current status and future directions in breast cancer. Oncologist 2006;11: 1047-1057.

5 Johnston S, Leary A: Lapatinib: a novel EGFR/ HER2 tyrosine kinase inhibitor for cancer. Drugs Today 2006;42:441-453.

6 Rusnak DW, Affleck K, Cockerill SG, Stubberfield C, Harris R, Page M, Smith KJ, Guntrip SB, Carter MC, Shaw RJ, Jowett A, Stables J, Topley P, Wood ER, Brignola PS, Kadwell SH, Reep BR, Mullin RJ, Alligood KJ, Keith BR, Crosby RM, Murray DM, Knight WB, Gilmer TM, Lackey K: The characterization of novel, dual ErbB-2/EGFR, tyrosine kinase inhibitors: potential therapy for cancer. Cancer Res 2001;61:7196-7203.

7 Burris HA 3rd: Dual kinase inhibition in the treatment of breast cancer. Initial experience with the EGFR/ErbB-2 inhibitor lapatinib. Oncologist 2004 9(suppl 3):10-15.

8 Nelson MH, Dolder CR: Lapatinib: a novel dual tyrosine kinase inhibitor with activity in solid tumors. Ann Pharmacother 2006;40:261-269.

$\checkmark 9$ Konecny GE, Pegram MD, Venkatesan N, Finn R, Yang G, Rahmeh M, Untch M, Rusnak DW, Spehar G, Mullin RJ, Keith BR, Gilmer TM, Berger M, Podratz KC, Slamon DJ: Activity of the dual kinase inhibitor lapatinib (GW572016) against HER-2overexpressing and trastuzumab-treated breast cancer cells. Cancer Res 2006;66:1630-1639.
10 Xia W, Liu H, Ho P, Spector N: Truncated ErbB2 receptor (p95ErbB2) is regulated by heregulin through heterodimer formation with ErbB3 yet remains sensitive to the dual EGFR/ErbB2 kinase inhibitor GW572016. Oncogene 2004;23:646-653.

11 Chu I, Blackwell K, Chen S, Slingerland J: The dual ErbB1/ErbB2 inhibitor, lapatinib (GW572016), cooperates with tamoxifen to inhibit both cell proliferation- and estrogen-dependent gene expression in antiestrogen-resistant breast cancer. Cancer Res 2005;65:18-25.

12 Zhou H, Kim YS, Peletier A, McCall W, Earp HS, Sartor CI: Effects of the EGFR/HER2 kinase inhibitor GW572016 on EGFR- and HER2-overexpressing breast cancer cell line proliferation, radiosensitization, and resistance. Int J Radiat Oncol Biol Phys 2004;58:344-352.

13 Burris HA 3rd, Hurwitz HI, Dees EC, Dowlati A, Blackwell KL, O'Neil B, Marcom PK, Ellis MJ, Overmoyer B, Jones SF, Harris JL, Smith DA, Koch KM, Stead A, Mangum S, Spector NL: Phase I safety, pharmacokinetics, and clinical activity study of lapatinib (GW572016), a reversible dual inhibitor of epidermal growth factor receptor tyrosine kinases, in heavily pretreated patients with metastatic carcinomas. J Clin Oncol 2005;23: 5305-5313.

14 Jones SF, Burris HA, Yardley DA, et al.: Lapatinib (an oral dual kinase inhibitor) plus weekly or every 3 week paclitaxel. Breast Cancer Res Treat 2004; 88:S64.

15 Storniolo A, Burris H, Pegram M, et al.: A phase I, open-label study of lapatinib (GW572016) plus trastuzumab; a clinically active regimen (abstr). Proc Am Soc Clin Oncol 2005;23:559.
16 Schwartz G, Chu QSC, Hammond LA, Mita M, Curtright J, Versola MJ, Koch K, Pandite LN, Ho PTC, Rowinsky EK: Phase I clinical, biology, and pharmacokinetic study of the combination of GW572016 and capecitabine in patients with advanced solid tumors. ASCO Annu Meet Proc, J Clin Oncol 2004;22(suppl 14S):3070.

17 Blackwell KL, Kaplan EH, Franco SX, et al.: A phase II, open-label, multi-center study of GW572016 in patients with trastuzumab-refractory metastatic breast cancer. J Clin Oncol 2004;22:3006.

18 Burstein H, Storniolo AM, Franco S, et al.: A phase II, open-label, multi-center study of lapatinib in two cohorts of patients with advanced or metastatic breast cancer who have progressed while receiving trastuzumab-containing regimens. Ann Oncol 2004; 15(suppl 3)

19 Blackwell KL, Burstein H, Pegram M, et al.: Determining relevant biomarkers from tissue and serum that may predict response to single agent lapatinib in trastuzumab refractory metastatic breast cancer. J Clin Oncol (meeting abstr) 2005;23:3004.

20 Gomez HL, Chavez MA, Doval DC, Chow LWC, Wood BA, Berger MS, Sledge GW: A phase II, randomized trial using the small molecule tyrosine kinase inhibitor lapatinib as a first-line treatment in patients with FISH positive advanced or metastatic breast cancer. ASCO Annu Meet Proc, J Clin Oncol 2005;23(suppl 16S):3046.

21 Geyer CE, Forster J, Lindquist D, Chan S, Romieu CG, Pienkowski T, Jagiello-Gruszfeld A, Crown J, Chan A, Kaufman B, Skarlos D, Campone M, Davidson N, Berger M, Oliva C, Rubin SD, Stein S, Cameron D: Lapatinib plus capecitabine for HER2-positive advanced breast cancer. N Engl J Med 2006;355:2733-2743. 